Copyright (2015) AIP Publishing. This article may be downloaded for personal use only. Any other use requires prior permission of the author and AIP Publishing. The following article appeared in Journal of Chemical Physics 21/142 (2015) p. 15101 and may be found at http://dx.doi.org/10.1063/1.4921388

\title{
Dissociative Electron Attachment to the Gas-Phase Nucleobase Hypoxanthine
}

\author{
M. Michele Dawley ${ }^{1, \dagger}$, Katrin Tanzer ${ }^{4, \dagger}$, Ian Carmichael ${ }^{1,3}$, Stephan Denifl ${ }^{4, a)}$, and \\ Sylwia Ptasińska ${ }^{1,2, a)}$ \\ ${ }^{1}$ Radiation Laboratory, ${ }^{2}$ Department of Physics, and ${ }^{3}$ Department of Chemistry and Biochemistry, \\ University of Notre Dame, Notre Dame, Indiana 46556, USA \\ ${ }^{4}$ Institut für Ionenphysik und Angewandte Physik, and Center for Molecular Biosciences Innsbruck (CMBI), \\ Leopold-Franzens Universität Innsbruck, Technikerstr. 25, A-6020 Innsbruck, Austria \\ $\dagger$ These authors contributed equally.
}

\section{ABSTRACT}

We present high-resolution measurements of the dissociative electron attachment (DEA) to isolated gas-phase hypoxanthine $\left(\mathrm{C}_{5} \mathrm{H}_{4} \mathrm{~N}_{4} \mathrm{O}, \mathrm{Hyp}\right)$, a tRNA purine base. The anion mass spectra and individual ion efficiency curves from Hyp were measured as a function of electron energy below $9 \mathrm{eV}$. The mass spectra at 1 and $6 \mathrm{eV}$ exhibit the highest anion yields, indicating possible common precursor ions that decay into the detectable anionic fragments. The $(\mathrm{Hyp}-\mathrm{H})$ anion $\left(\mathrm{C}_{5} \mathrm{H}_{3} \mathrm{~N}_{4} \mathrm{O}^{-}\right)$ exhibits a sharp resonant peak at $1 \mathrm{eV}$, which we tentatively assign to a dipole-bound state of the keto-N1H,N9H tautomer in which dehydrogenation occurs at either the N1 or N9 position based upon our quantum chemical computations, (B3LYP/6-311+G(d,p) and U(MP2-aug-cc-pVDZ+)), and prior studies with adenine. This closed-shell dehydrogenated anion is the dominant fragment formed upon electron attachment, as with other nucleobases. Seven other anions were also

\footnotetext{
a) Authors to whom correspondence should be addressed.

Sylwia Ptasińska - Electronic mail: Sylwia.Ptasinska.1@nd.edu. Telephone: +1 5746314506.

Postal Address: Radiation Laboratory, University of Notre Dame, Notre Dame, IN 46556 USA.

Stephan Denifl - Electronic mail: Stephan.Denifl@uibk.ac.at. Telephone: +4351250752662.

Postal Address: Institut für Ionenphysik, Leopold Franzens Universität Innsbruck, Technikerstr. 25, A-6020 Innsbruck, Austria.
} 
observed including (Hyp - NH) $)^{-}, \mathrm{C}_{4} \mathrm{H}_{3} \mathrm{~N}_{4}^{-} / \mathrm{C}_{4} \mathrm{HN}_{3} \mathrm{O}^{-}, \mathrm{C}_{4} \mathrm{H}_{2} \mathrm{~N}_{3}^{-}, \mathrm{C}_{3} \mathrm{NO}^{-} / \mathrm{HC}(\mathrm{HCN}) \mathrm{CN}^{-}, \mathrm{OCN}^{-}$, $\mathrm{CN}^{-}$, and $\mathrm{O}^{-}$. Most of these anions exhibit broad but weak resonances between 4 and $8 \mathrm{eV}$ similar to many analogous anions from adenine. The DEA to Hyp involves significant fragmentation, which is relevant to understanding radiation damage of biomolecules.

\section{KEYWORDS}

anion, negative ion, nucleobase, low-energy electron, ion efficiency curve, purine, DEA, DNA, DFT, MP2, B3LYP

\section{INTRODUCTION}

The fields of radiation chemistry and biophysics are generally interested in low-energy electron interactions with biological molecules because such electrons are the most abundant secondary particles arising from ionizing radiation. Secondary particles, and specifically low-energy electrons, from ionizing radiation are responsible for many of the lethal or mutagenic effects on genetic information in living cells [1]. Dissociative electron attachment (DEA) is the only resonant process that can result in selective bond cleavage of biomolecules [2-5] at low electron energies $(<10 \mathrm{eV})$ and is thought to be the dominant process responsible for the mutagenic effects in cells [6]. The DEA mechanism has been extensively discussed previously regarding gas-phase studies of biomolecules [4, 7-9]. Briefly, DEA involves the low-energy electron capture by a molecule (AB) to produce a transient negative ion (TNI) state that can then dissociate into anions $\left(\mathrm{A}^{-}\right)$and neutral radicals $\left(\mathrm{B}^{\circ}\right)$, according to the following general scheme:

$e^{-}+\mathrm{AB} \leftrightarrow(\mathrm{AB})^{-\#} \rightarrow \mathrm{A}^{-}+\mathrm{B}^{\cdot}$

Sanche et al. demonstrated that low-energy electrons (3-20 eV), via the DEA process, can effectively induce single- and double-strand breaks in DNA, which is composed of nitrogenous bases, deoxyribose sugar moieties, and phosphate groups surrounded by water [10]. It has been suggested 
that DNA damage can be due to the decay of TNIs of the sugar-phosphate backbone or of the nucleobases into more basic molecular components [1, 10, 11]. Furthermore, low-energy electrons have been shown to specifically damage nucleic acids and nucleobases $[2,12]$. Several gas-phase studies over the last decade have reported that electrons with energies well below the ionization energies of the nucleobases can induce DEA. The DEA processes of adenine (Ade) [2, 5, 12-15], guanine (Gua) [2, 15, 16], cytosine (Cyt) [15, 17], thymine (Thy) [3, 13, 15, 17, 18], and uracil (Ura) $[18,19]$ have all been investigated extensively and demonstrate that these molecules are quite fragile and susceptible to fragmentation even at electron energies of $\sim 1 \mathrm{eV}$ [11]. Many of these studies have shown that precise control of the electron energy can induce chemical reactions selectively. Interestingly, the DEA process of the purine derivative, hypoxanthine (Hyp), has been overlooked until now. The two dominant tautomeric structures of Hyp are shown in Fig. 1, along with the structure of the most stable tautomer of Ade in the gas phase for comparison. Hyp serves as the nucleobase that is attached to the ribose sugar in inosine (I), which is an important nucleoside involved in the genetic code translation in cells. Hyp is also a versatile component of the wobble base pairs in the RNA secondary structure because three of the four wobble base pairs that bond two nucleotides in RNA contain Hyp: Hyp-Ura, Hyp-Ade, and Hyp-Cyt [20]. Because Hyp has the ability to bind to several other nucleobases, it is considered to be a universal nucleobase [21]. The resulting tRNA molecules that can contain Hyp link DNA and RNA sequences with amino acids of a growing peptide chain during protein synthesis. Thus, Hyp has an important role in protein synthesis and is likely damaged similarly to the DNA nucleobases upon ionizing radiation. Additionally, Hyp can also result from the deamination of Ade in DNA via mutagenic processes.

In this work, we investigate the DEA to Hyp for the first time using a high-resolution electron energy apparatus coupled to a quadrupole mass spectrometer. The prior DEA studies to Ade $[2,5,16]$ and other nucleobases $[2,3,19,22,23]$, including Gua, which have similar chemical structures to 
Hyp, will be discussed and compared with the present results. The pyrimidine bases, Cyt and Thy, will also be discussed in relation to some fragments. Quantum chemical calculations of the various tautomers of Hyp were also performed to assist with the interpretation of the $(\mathrm{Hyp}-\mathrm{H})^{-}$formation. 


\section{METHODS}

\subsection{Experimental Details}

The DEA to Hyp was investigated in a high vacuum chamber (base pressure $\sim 8 \times 10^{-8}$ mbar) at the Nano-Bio-Physics laboratory in Innsbruck. We have described this instrument in detail in several previous publications [24-27]. Hyp $\left(\mathrm{C}_{5} \mathrm{H}_{4} \mathrm{~N}_{4} \mathrm{O}, M=136 \mathrm{~g} / \mathrm{mol}\right)$, a white crystalline powder, was purchased from Sigma-Aldrich (Vienna, Austria) and had a stated purity of $\geq 99 \%$. Briefly, inside the vacuum chamber, a molecular beam of Hyp was formed from a capillary that is attached to a copper oven. The molecular beam was crossed at a $90^{\circ}$ angle in the collision region with an electron beam produced by a high-resolution hemispherical electron monochromator (HEM). During these experiments, the energy resolution of the electron beam was typically 100-140 meV (full width at half maximum (FWHM)), and the electron beam had an electron current of $\sim 10 \mathrm{nA}$. Within the vacuum chamber, the Hyp powder was heated to $453 \pm 3 \mathrm{~K}$ inside the copper oven to sufficiently sublimate the sample to produce the neutral molecular beam at a working pressure of $\sim 2 \times 10^{-7}$ mbar. The sample was heated with care to avoid its melting point $(\sim 573 \mathrm{~K})$ and also to prevent thermal decomposition (see our previous publication for details [26]). During the measurements, the chamber was heated to approximately $350 \mathrm{~K}$ by using internal lamps to prevent molecular condensation on the lenses of the HEM. A quadrupole mass spectrometer (QMS) extracted and detected the anions that were formed upon the interaction of Hyp with the electrons in the collision region of the HEM.

The experiments were performed as follows. Cation mass spectra $(70 \mathrm{eV})$ were obtained as a function of increasing temperature until the Hyp parent cation was observed with a relatively high signal. Then the oven was kept constant at that temperature $(\sim 453 \mathrm{~K})$. Anion mass spectra were then obtained to determine the anions formed at each electron energy from $0-10 \mathrm{eV}$ at $1 \mathrm{eV}$ intervals. For each anion observed in the mass spectra, ion efficiency curves were recorded while scanning the electron energy from $0-9 \mathrm{eV}$. Typically, for each anion observed, $\sim 30$ energy scans were obtained and 
averaged depending upon the ion yield. The electron-energy scale was calibrated by introducing $\mathrm{CCl}_{4}$ to a pressure of $\sim 2 \times 10^{-6}$ mbar into the chamber and measuring the ion efficiency curves of $\mathrm{m} / \mathrm{z} 35$ for $\mathrm{Cl}^{-}$before and after each Hyp measurement. The anion, $\mathrm{Cl}^{-}$, is formed from $\mathrm{CCl}_{4}$ according to the following well-known DEA reaction:

$e^{-}+\mathrm{CCl}_{4} \leftrightarrow\left(\mathrm{CCl}_{4}\right)^{-\#} \rightarrow \mathrm{Cl}^{-}+\mathrm{CCl}_{3}^{\cdot}$

The $\mathrm{Cl}^{-}$has a distinct resonant peak at $0 \mathrm{eV}$ that was used to calibrate the energy scale [28].

\subsection{Computational Details}

Quantum chemical calculations were performed to understand the formation of the $(\mathrm{Hyp}-\mathrm{H})$ anion in which hydrogen loss can occur from different positions on the molecule depending upon the tautomer. Hyp is known to exist as several distinct keto and enol tautomers in different states (gas phase vs. aqueous phase) in which the base structure is the same but a hydrogen can be in different locations, as shown by prior computations $[21,29,30]$. Although our gas-phase experiments could not differentiate between the tautomers, prior computations have shown that the keto-N1H,N7H tautomer of Hyp (in which the hydrogen is on N7 rather than N9 in the imidazole ring, see Fig. 1) has the lowest relative energy and represents $81 \%$ of the population in the gas phase at room temperature [21, 29 , 31]. An experimental ultraviolet photoelectron spectroscopy (UPS) study reported results that also support those theoretical studies [32]. It has been previously shown that the keto-N1H,N9H tautomer, also shown in Fig. 1, is only $\sim 0.92 \mathrm{kcal} / \mathrm{mol}(0.04 \mathrm{eV})$ higher in energy and represents $18 \%$ of the population in the gas phase at room temperature. However, all the enol tautomers were found to be less stable [21]. Thus, the keto forms of Hyp have been found to be dominant in the gas phase. Our present calculations are in agreement with the previous results obtained regarding the relative stability of the neutral Hyp tautomers at room temperature [33]. We note that the Hyp sample in our experiment was at $453 \mathrm{~K}$, and this higher temperature may result in an increase in the keto- $\mathrm{N} 1 \mathrm{H}, \mathrm{N} 9 \mathrm{H}$ 
tautomer population. Prior calculations of the tautomeric equilibrium constants in the gas phase at $298 \mathrm{~K}$ vs. $480 \mathrm{~K}$ have suggested that the initially unfavorable population of keto-N1H,N9H tautomers increased significantly in relative contribution when the temperature was increased to $480 \mathrm{~K}$ (from 0.285 to 0.464 , respectively) [33]. In our computations, we have also determined the dipole moments of the neutral tautomers of Hyp, searched for dipole-bound anions, computed bond dissociation energies, and determined the reaction enthalpies for the dissociation of hydrogen atoms from the neutral Hyp tautomers.

The computations were performed as follows. The tautomers were labeled through the location of the nitrogen and/or oxygen bound hydrogens. There are six keto- forms and eight enol- forms, with the $\mathrm{OH}$ pointing either away from (enol-1) or towards (enol-2) the five-membered ring. All structures were optimized by Density Functional Theory (DFT), and calculations were conducted within Gaussian09 [34] using Becke's standard three-parameter functional, denoted B3LYP [35], together with analytic energy gradients. Calculations completed with previous versions of the Gaussian software were rerun to ensure consistency through the use of identical functional numerical integration grids. A Pople-style basis set of valence triple-zeta quality, denoted $6-311+G(d, p)$ [36], was used, which includes a set of diffuse s- and p-functions on each non-hydrogen atom and polarization d- and p-functions, the latter on each hydrogen atom. The nature of the stationary points obtained was checked by calculating the analytic Hessians to ensure the absence of imaginary frequencies, indicating that at least local minima had been reached. All of these local minima proved to be planar except for the enol-1,NH1 structure where steric repulsions induced non-planarity. Enthalpies for the dissociation of hydrogen atoms from the electron-attached Hyp were constructed by first calculating the appropriate bond dissociation energies in the neutral molecule, then subtracting the computed electron affinity of the resulting radical species, and finally making the relevant thermochemical corrections to account for both zero-point vibrational motions and state populations. Because the 
experimental conditions were at $453 \mathrm{~K}$, we determined the temperature effects on the computed enthalpies. As an example, for the keto-N1H,N9H dissociation, we found a change in enthalpy of approximately $0.8 \mathrm{eV}$ from 300 to $500 \mathrm{~K}$ for both reactants and products. Exploratory calculations to determine the propensity for formation of dipole-bound anion states in the various tautomers were conducted roughly following the protocol outlined by Desfrançois et al. [37] using second-order Møller-Plesset perturbation theory (U(MP2-aug-cc-pVDZ+)) but employing atom-centered basis functions from the augmented correlation consistent sets of Dunning and coworkers [38] and suitably-located off-molecule diffuse $s, p$-sets.

\section{RESULTS AND DISCUSSION}

\subsection{Anion Mass Spectra}

Fig. 2 presents the anion mass spectra for Hyp at electron energies of 1 and $6 \mathrm{eV}$. At $1 \mathrm{eV}$, the only anion from the sample is $\mathrm{m} / \mathrm{z} 135$, which we assign to the principal anion $\mathrm{C}_{5} \mathrm{H}_{3} \mathrm{~N}_{4} \mathrm{O}^{-}$or $(\mathrm{Hyp}-\mathrm{H})^{-}$. The two peaks at $\mathrm{m} / \mathrm{z} 35$ and $\mathrm{m} / \mathrm{z} 37$ are due to $\mathrm{Cl}^{-}$from the residual $\mathrm{CCl}_{4}$ calibration gas, which always remained in the chamber, and these peaks are present in all mass spectra. In contrast to the mass spectrum at $1 \mathrm{eV}$, the mass spectrum recorded at $6 \mathrm{eV}$ shows the fragmentation of Hyp, comparable to that previously reported for Ade [5]. Several of the most abundant fragment anions observed in this work have corresponding masses found in the Ade anion mass spectrum [5], which is not surprising, considering their similar purine structures. We have assigned some of the observed Hyp anions based upon analogous anions observed in the Ade DEA study [5]. At $6 \mathrm{eV}$, the anions observed from Hyp include: $\mathrm{m} / \mathrm{z} 16$ assigned to $\mathrm{O}^{-}, \mathrm{m} / \mathrm{z} 26$ assigned to $\mathrm{CN}^{-}, \mathrm{m} / \mathrm{z} 42$ assigned to $\mathrm{OCN}^{-}$, $\mathrm{m} / \mathrm{z} 66$ assigned to $\mathrm{C}_{3} \mathrm{NO}^{-} / \mathrm{HC}(\mathrm{HCN}) \mathrm{CN}^{-}, \mathrm{m} / \mathrm{z} 92$ assigned to $\mathrm{C}_{4} \mathrm{H}_{2} \mathrm{~N}_{3}^{-}$, and $\mathrm{m} / \mathrm{z} 107$ assigned to $\mathrm{C}_{4} \mathrm{H}_{3} \mathrm{~N}_{4}^{-} / \mathrm{C}_{4} \mathrm{HN}_{3} \mathrm{O}^{-}$. The anions at $\mathrm{m} / \mathrm{z} 92$ and $\mathrm{m} / \mathrm{z} 26$ are the most intense above $5 \mathrm{eV}$. Additionally, at $6 \mathrm{eV},(\mathrm{Hyp}-2 \mathrm{H})^{-}$is observed, although in a very low abundance. Table 1 includes the peak 
positions of the resonances and most likely anion molecular formulas for all the anions observed from Hyp in this study compared to those from the Ade DEA study reported by Huber et al. [5]. The assignments proposed here could be clarified using future detailed quantum chemical calculations.

\section{2 (Hypoxanthine $-\mathrm{H}$ ) anion}

Fig. 3 presents the ion efficiency curve of $m / z 135$ for $(\mathrm{Hyp}-\mathrm{H})^{-}$, which is formed according to the following reaction, in which a hydrogen radical is produced:

$e^{-}+\mathrm{C}_{5} \mathrm{H}_{4} \mathrm{~N}_{4} \mathrm{O} \leftrightarrow\left(\mathrm{C}_{5} \mathrm{H}_{4} \mathrm{~N}_{4} \mathrm{O}\right)^{-\#} \rightarrow \mathrm{C}_{5} \mathrm{H}_{3} \mathrm{~N}_{4} \mathrm{O}^{-}+\mathrm{H}^{\cdot}$

The ion efficiency curve for $(\mathrm{Hyp}-\mathrm{H})^{-}$is compared in Fig. 3 to $\mathrm{m} / \mathrm{z} 134$ for (Ade - H) ${ }^{-}$produced upon electron attachment to Ade at a similar $110 \mathrm{meV}$ resolution (previously unpublished), with both exhibiting resonances from $0.7-3 \mathrm{eV}$. Dehydrogenation could occur from different locations on the parent Hyp molecule depending upon which tautomer is dominant under our experimental conditions. For the keto-N1H,N7H tautomer, hydrogen loss could occur from N1, C2, C8, or N7. For the keto-N1H,N9H tautomer, hydrogen loss could occur from N1, C2, C8, or N9. These two tautomers, as mentioned above, make up the majority of the population in the gas phase. Experiments with other nucleobases have all shown a characteristic sharp resonance at $\sim 1 \mathrm{eV}$ and broader structures at higher energies [14] for the (Parent - H) anion, which have been attributed to the exclusive loss of hydrogen from nitrogen sites of the nucleobases [3, 15, 23]. Considering the structural similarities between nucleobases, dehydrogenation at a nitrogen site of Hyp to form the closed-shell anion, $\left(\mathrm{C}_{5} \mathrm{H}_{3} \mathrm{~N}_{4} \mathrm{O}\right)^{-}$, is also likely and may suggest site and bond selectivity for this reaction. Isotopic studies with Ade concluded that dehydrogenation at the $\mathrm{C} 2$ position did not occur [14] and thus further supports loss from the nitrogen sites. For Thy, isotopic studies [15] and methylated Thy studies [23] also confirmed that at low-electron energies the N-H bonds selectively dissociate. Thus, we will primarily discuss hydrogen loss from the nitrogen sites on Hyp. 
The ion efficiency curves for the principal (Parent $-\mathrm{H})^{-}$fragments from Ade and Hyp both exhibit sharp peaks at $\sim 1.1 \mathrm{eV}$ and other weaker features below $3 \mathrm{eV}$; however, the relative abundances of these features differs between the two molecules. The molecular formulas of the (Parent $-\mathrm{H}$ ) anions of Ade and Hyp are quite different $\left(\mathrm{C}_{5} \mathrm{H}_{4} \mathrm{~N}_{5}^{-}\right.$vs. $\mathrm{C}_{5} \mathrm{H}_{3} \mathrm{~N}_{4} \mathrm{O}^{-}$, respectively), and the parent molecules have different dominant tautomers in the gas phase (the $\mathrm{N} 1 \mathrm{H}, \mathrm{N} 9 \mathrm{H}$ tautomer for Ade vs. the keto-N1H,N7H for Hyp [39]) at $298 \mathrm{~K}$, as mentioned above, which may result in hydrogen loss from different positions on the parent molecule. The sharp $\sim 1 \mathrm{eV}$ structure has been assigned as dipole-supported vibrational Feshbach resonances in the case of Thy and Ura [14, 40, 41]. However, recent time-resolved photoelectron imaging experiments of Ura have explored the electron attachment mechanism for the resonances observed near $1 \mathrm{eV}$ and showed that the electron can attach directly to the valence bound state, rather than needing a doorway dipole-bound anion [42]. Gohlke et al. attributed the resonance to formation of $(\text { Ade })^{-\#}$ via electron capture on the lowest $\pi^{*}$ antibonding orbital of the Ade neutral molecule before dissociation into (Ade $-\mathrm{H}^{-}$[12]. However, Denifl et al. suggested that this sharp resonant peak in the case of Ade is due to crossing of the potential energy curves of the lowest $\sigma$ excited state and the dipole-bound state [14] and are due to loss of $\mathrm{H}$ from the N9 position. Furthermore, when the N9 position was methylated in the Ade experiments, the large sharp resonance just above $1 \mathrm{eV}$ disappeared, supporting the proposal that this peak is due to hydrogen loss from the N9 position [14]. Hydrogen loss from the N9 position in Hyp may occur if our sample is a mixture of the two dominant tautomeric forms. To further determine which reaction is more favorable, we calculated the reaction enthalpies for hydrogen loss from the two different Hyp tautomers. For the keto-N1H,N7H tautomer, hydrogen loss from the N7 position results in an enthalpy of $0.80 \mathrm{eV}$. Whereas for the keto-N1H,N9H tautomer, hydrogen loss from the N9 position is only slightly lower with an enthalpy of $0.77 \mathrm{eV}$, indicating that the two tautomers are approximately isoenergetic. However, the bond dissociation energy (BDE) for N9-H cleavage in the keto-N1H,N9H 
tautomer was found to be $4.49 \mathrm{eV}$, while the BDE for N7-H cleavage in the keto-N1H,N7H tautomer was found to be slightly higher at $4.52 \mathrm{eV}$, indicating that the $\mathrm{N} 9-\mathrm{H}$ bond is weaker in the keto-N1H,N9H Hyp tautomer. Computations of the bond lengths, which could correlate with the bond strengths, showed that the N7-H and the N9-H bonds in the respective tautomers both had very similar lengths of $1.009 \AA$. However, we also calculated the dipole moments to be $1.6 \mathrm{D}$ for the keto-N1H,N7H and 5.3 D for the keto-N1H,N9H tautomer. The very low dipole moment of the keto-N1H,N7H tautomer suggests that an electron would not easily become trapped in a diffuse bound state of this tautomer form, even if it is dominant in our gas-phase experiments. In prior works, the dipole moment of the keto-N1H,N7H Hyp tautomer has also been calculated to be lower (at 1.21-1.88 D) [31] than that of the keto-N1H,N9H Ade tautomer (2.36-2.53 D [14, 31]), and the critical dipole moment is 2 to 2.5 Debye to form dipole-bound anion states that can then give rise to vibrational Feshbach resonances [40]. Our calculations resulted in a dipole moment of 2.45 D (B3LYP) or 2.51 D (MP2) for the keto-N1H,N9H Ade tautomer. Also, preliminary computational searches for dipole-bound anions revealed a weakly attached electron in the keto-N1H,N9H Hyp tautomer (see Fig. 4) and, as expected from the computed dipole moment of Hyp, we failed to locate such a state in the keto-N1H,N7H form of Hyp. The electron affinity for this dipole-bound anion (somo) was calculated to be $17 \mathrm{meV}$ using the U(MP2-aug-cc-pVDZ+) method. Thus, we tentatively propose that the resonance at $1.1 \mathrm{eV}$ for the $(\mathrm{Hyp}-\mathrm{H})^{-}$arises from a dipole-bound state, as suggested previously for Ade by Denifl et al.[14], in which hydrogen loss occurs at either the N9 or N1 position of the keto-N1N,N9H tautomer population. Of note, the reaction enthalpies for hydrogen loss from the N1 position were both higher at $0.95 \mathrm{eV}$ and $1.05 \mathrm{eV}$ for the keto-N1H,N7H and keto-N1H,N9H tautomers, respectively, suggesting that hydrogen loss from the $\mathrm{N} 1$ position in either tautomer is slightly less favored although still possible within this threshold. We also observed in our calculations that the lowest relative energy radical is the keto- $\mathrm{N} 1 \mathrm{H}$ (hydrogen atom loss at the $\mathrm{N} 1 \mathrm{H}$ ) radical from 
Hyp, while the keto-N7H and the keto-N9H radicals were both slightly higher in energy at $13 \mathrm{~kJ} / \mathrm{mol}$ $(0.14 \mathrm{eV})$. The Hyp deprotonated anions also had energies of 15 and $27 \mathrm{~kJ} / \mathrm{mol}(0.16$ and $0.28 \mathrm{eV})$ for the keto-N7H and the keto-N9H tautomers, respectively, relative to the keto-N1H tautomer. Therefore, we cannot rule out cleavage at the N1 position with our present experiments and calculations.

The ion efficiency curve for $(\text { Ade }-\mathrm{H})^{-}$in Fig. 3 shows additional features at $0.9 \mathrm{eV}$ and a shoulder at $1.4 \mathrm{eV}$; however, although present, these features are not clearly resolved for $(\mathrm{Hyp}-\mathrm{H})^{-}$ possibly due to a slightly lower electron energy resolution in our study. Denifl et al. demonstrated clearly using methylated Ade that the shoulder near $1.5 \mathrm{eV}$ is due to $\mathrm{H}$ loss from the $\mathrm{N} 9$ position in Ade [14]. Additionally, as shown in Fig. 3, the (Ade $-\mathrm{H})^{-}$has a much larger ion yield than the $(\mathrm{Hyp}-\mathrm{H})^{-}$, which could be partially due to the fact that the N9-H keto tautomer makes up $100 \%$ of the population of Ade in the gas phase at room temperature [43]. If the dominant Hyp tautomer in the gas phase is the keto-N1H,N7H tautomer but its low dipole moment precludes the formation of a dipole-bound state, then the features near $1 \mathrm{eV}$ for the $(\mathrm{Hyp}-\mathrm{H})$ anion would be expected to have a much lower ion yield if they primarily arise from the minor keto-N1H,N9H tautomer. We do observe this, and it may support the argument that the anion results from hydrogen loss from the N9 position of the Hyp keto-N1H,N9H tautomer.

Minaev et al. suggested that the $2.2 \mathrm{eV}$ peak for Ade is correlated to the N-H bond cleavage in the amino group [16]. However, in the case of Hyp, we observe this broad peak in weak abundance, and in the case of Ade, prior experiments with 6-dimethyladenine, in which the N-Hs were replaced with $\mathrm{N}-\mathrm{CH}_{3}$ groups, also still showed this peak [14]. This suggests that this resonance does not arise from $\mathrm{N}-\mathrm{H}$ bond cleavage but instead due to dehydrogenation from a location on the ring structure itself.

Additionally, a low-intensity peak at $0.03 \mathrm{eV}$ was observed for $(\mathrm{Hyp}-\mathrm{H})^{-}$, similar to the low-intensity $0.08 \mathrm{eV}$ peak for $(\mathrm{Ade}-\mathrm{H})^{-}$. In the case of Ade, Huber et al. suggested this peak near 
$0 \mathrm{eV}$ may arise from the endothermic DEA reaction to vibrationally excited Ade or a hot band transition $[5,12]$. They ruled out ion-molecule reactions with $\mathrm{SF}_{6}^{-}[12]$, as do we, because $\mathrm{SF}_{6}$ was not used as the calibration gas. An alternative assignment was given for the DEA to Thy, where it was concluded that such a weak resonance near $0 \mathrm{eV}$ was due to $\mathrm{H}_{2}$ loss from Thy that contains ${ }^{13} \mathrm{C}[3,17]$.

\subsection{Other anions}

Fig. 5 presents the ion efficiency curve for $m / z$ 121, which is assigned to $(\mathrm{Hyp}-\mathrm{NH})^{-}$. This anion is the only other anion besides the $(\mathrm{Hyp}-\mathrm{H})^{-}$that has resonant peaks below $3 \mathrm{eV}$, and it has a lower intensity than most of the other major anions $\left(0.9\right.$ relative to the $\left.(\mathrm{Hyp}-\mathrm{H})^{-}\right)$. The ion efficiency curve of $(\mathrm{Hyp}-\mathrm{NH})^{-}$has a broad structure with two overlapping resonant peaks with maxima at 1.5 and $2.0 \mathrm{eV} .(\mathrm{Hyp}-\mathrm{NH})^{-}$is formed according to the following reaction:

$e^{-}+\mathrm{C}_{5} \mathrm{H}_{4} \mathrm{~N}_{4} \mathrm{O} \leftrightarrow\left(\mathrm{C}_{5} \mathrm{H}_{4} \mathrm{~N}_{4} \mathrm{O}\right)^{-\#} \rightarrow\left(\mathrm{C}_{5} \mathrm{H}_{3} \mathrm{~N}_{3} \mathrm{O}\right)^{-}+\mathrm{NH}^{\cdot}$

However, unlike the DEA to Ade, we did not observe the loss of a $\mathrm{NH}_{2}$ group or a $\mathrm{NH}_{3}$ molecule from Hyp ( $/ \mathrm{m} / \mathrm{z} 119$ or 118 , respectively). This is expected since in Hyp the $\mathrm{NH}_{2}$ group is replaced with oxygen $(=\mathrm{O})$ bonded to $\mathrm{C} 6$.

Fig. 6 presents the ion efficiency curves for the anions produced upon electron attachment to Hyp with peak maxima between 5 and $7 \mathrm{eV}$ that most likely arise from core-excited resonances. These fragment anions include: $\mathrm{m} / \mathrm{z} 107\left(\mathrm{C}_{4} \mathrm{H}_{3} \mathrm{~N}_{4}{ }^{-} / \mathrm{C}_{4} \mathrm{HN}_{3} \mathrm{O}^{-}\right), \mathrm{m} / \mathrm{z} 92\left(\mathrm{C}_{4} \mathrm{H}_{2} \mathrm{~N}_{3}{ }^{-}\right), \mathrm{m} / \mathrm{z} 66\left(\mathrm{C}_{3} \mathrm{NO}^{-}\right.$/ $\left.\mathrm{HC}(\mathrm{HCN}) \mathrm{CN}^{-}\right), \mathrm{m} / \mathrm{z} 42\left(\mathrm{OCN}^{-}\right), \mathrm{m} / \mathrm{z} 26\left(\mathrm{CN}^{-}\right)$, and $\mathrm{m} / \mathrm{z} 16\left(\mathrm{O}^{-}\right)$. Several other nucleobases have also shown complex decomposition in the energy range from $4-9 \mathrm{eV}[5,19]$. The anion at $\mathrm{m} / \mathrm{z} 107$ exhibits two overlapping resonances at 5.0 and $5.7 \mathrm{eV} . \mathrm{C}_{4} \mathrm{H}_{3} \mathrm{~N}_{4}{ }^{-}$from Ade at $\mathrm{m} / \mathrm{z} 107$ also exhibits at peak at $5.7 \mathrm{eV}$ [5]. In the case of Hyp, the following two reactions could form the anion at $\mathrm{m} / \mathrm{z} 107$ :

$$
\begin{aligned}
& e^{-}+\mathrm{C}_{5} \mathrm{H}_{4} \mathrm{~N}_{4} \mathrm{O} \leftrightarrow\left(\mathrm{C}_{5} \mathrm{H}_{4} \mathrm{~N}_{4} \mathrm{O}\right)^{-\#} \rightarrow\left(\mathrm{C}_{4} \mathrm{H}_{3} \mathrm{~N}_{4}\right)^{-}+\mathrm{HCO} \\
& e^{-}+\mathrm{C}_{5} \mathrm{H}_{4} \mathrm{~N}_{4} \mathrm{O} \leftrightarrow\left(\mathrm{C}_{5} \mathrm{H}_{4} \mathrm{~N}_{4} \mathrm{O}\right)^{-\#} \rightarrow\left(\mathrm{C}_{4} \mathrm{HN}_{3} \mathrm{O}\right)^{-}+\mathrm{HCN}+\mathrm{H}_{2}
\end{aligned}
$$


The anion at $\mathrm{m} / \mathrm{z} 107$ that was observed in the DEA to Ade was suggested to form via $\mathrm{HCN}$ and $\mathrm{H}$ loss because it is the most energetically favorable pathway [5]. In the case of Hyp, an additional $\mathrm{H}$ atom would be lost to exothermically form $\mathrm{H}_{2}$, as in reaction (6). However, other neutral-loss possibilities include the ejection of a $\mathrm{CN}$ radical $+3 \mathrm{H}$ or $\mathrm{HCN}+2 \mathrm{H}$, but these reaction pathways are less favorable thermodynamically.

The anion at $\mathrm{m} / \mathrm{z} 92$ assigned to $\mathrm{C}_{4} \mathrm{H}_{2} \mathrm{~N}_{3}{ }^{-}$also exhibits two overlapping broad resonances at 5.0 and $6.0 \mathrm{eV}$ similar to those observed for the same anion at $\mathrm{m} / \mathrm{z} 92$ from Ade in which two resonances (at $5.6 \mathrm{eV}$ and $6.7 \mathrm{eV}$ ) were identified. Likewise, the anion at $\mathrm{m} / \mathrm{z} 66$ from Hyp, which we assign to $\mathrm{C}_{3} \mathrm{NO}^{-} / \mathrm{HC}(\mathrm{HCN}) \mathrm{CN}^{-}$, exhibits a broad resonance with a peak maximum at $6.3 \mathrm{eV}$. The $\mathrm{HC}(\mathrm{HCN}) \mathrm{CN}^{-}$could arise from the cleavage of the intact imidazole ring of Hyp. The shape and position of its resonant peak is similar to that of Ade's $m / z$, which was assigned to $\mathrm{HCN}(\mathrm{CN})_{2}^{-}$by Huber et al. [5].

The anion at $\mathrm{m} / \mathrm{z} 42$ assigned to $\mathrm{OCN}^{-}$has been extensively observed in several other nucleobase DEA studies $[2,5,18,19]$. The $\mathrm{OCN}^{-}$is formed due to the high electron affinity of OCN $(3.61 \mathrm{eV})[44,45]$ and can result from complex dissociation (multiple bond breakage) of the 6-membered ring of Hyp. Here, in contrast to many other studies, we observe a very weak, broad resonance $\left(0.9\right.$ relative abundance to the $\left.(\mathrm{Hyp}-\mathrm{H})^{-}\right)$at $6.4 \mathrm{eV}$, and we note that $\mathrm{OCN}^{-}$was not observed in the DEA to Ade because it lacks oxygen [5]. This anion was observed in the case of Gua, which has a similar purine structure as Hyp, but it exhibited several resonances below $5 \mathrm{eV}$ [2]. Additionally, $\mathrm{OCN}^{-}$was observed in the DEA to Thy with a resonance at $6.81 \mathrm{eV}$ among others, and it was also observed in the DEA to Cyt with a resonance at $5.98 \mathrm{eV}$ among others [17].

$\mathrm{CN}^{-}$from Hyp also has a broad resonant structure with two overlapping peaks at 5.3 and $6.2 \mathrm{eV}$, and this anion is also often observed in measurements of electron attachment to nucleobases [2] because of the high electron affinity of $\mathrm{CN}(3.86 \mathrm{eV})$ [46]. The $\mathrm{CN}^{-}$is formed due to complex 
excision via the breaking of multiple bonds in Hyp. The $\mathrm{CN}^{-}$from Ade, which should be comparable, also exhibited two broad overlapping peaks at 5.8 and $6.7 \mathrm{eV}$ in the Huber et al. study [5]. The $\mathrm{CN}^{-}$ resonances from both Hyp and Ade near $6 \mathrm{eV}$ are similar but have different shaped leading edges. The $\mathrm{CN}^{-}$is the dominant peak above $5 \mathrm{eV}$ in the DEA to Ade; however, $\mathrm{m} / \mathrm{z} 92$ is slightly more intense above $5 \mathrm{eV}$ in the DEA to Hyp. In the cases of the purine bases, Thy and Cyt, resonances due to $\mathrm{CN}^{-}$ were observed at 6.94 and $6.77 \mathrm{eV}$, respectively, among several other peaks [17].

Finally, as shown in Fig. 6, $\mathrm{O}^{-}$is observed at $\mathrm{m} / \mathrm{z} 16$ with a broad resonance at $6.6 \mathrm{eV}$. To compare to other purines, for Gua, the $\mathrm{O}^{-} / \mathrm{NH}_{2}{ }^{-}$observed by Abdoul-Carime et al. showed a resonance at $\sim 6.2 \mathrm{eV}$, and a resonance at $\sim 2 \mathrm{eV}$ was assigned to $\mathrm{NH}_{2}^{-}$. Taking now the direct comparison of the present $\mathrm{O}^{-}$with the same $\mathrm{m} / \mathrm{z}$ for Gua from ref. [2], the $\sim 6.2 \mathrm{eV}$ resonance in their ion yield was likely due to $\mathrm{O}^{-}$. Although Ade does not contain oxygen and thus $\mathrm{O}^{-}$would not be expected, $\mathrm{NH}_{2}^{-}$would be expected similar to Gua. However, the $\mathrm{NH}_{2}{ }^{-}$resonance was not reported in the studies of the DEA to Ade $[2,5]$. The $\mathrm{O}^{-}$from the pyrimidine, Thy, which does not contain $\mathrm{NH}_{2}$ functionalities, exhibited resonances at 9.8 and $12.36 \mathrm{eV}$ [17]. Also in the DEA to Cyt, a sharp resonance was observed at $5.74 \mathrm{eV}$ for $\mathrm{m} / \mathrm{z} 16$, but because Cyt also contains the amino functional group, it could have resulted from either $\mathrm{NH}_{2}^{-}$or $\mathrm{O}^{-}[17]$. 


\section{CONCLUSIONS}

We have measured the anions resulting from the DEA to gas-phase Hyp as a function of electron energy below $9 \mathrm{eV}$. Hyp is sensitive to dissociation at sub-ionization electron energies, involving cleavage of simple bonds as well as complex cleavage of the parent ring structure. The Hyp parent anion is not formed in the present DEA experiments in any measurable quantity above the ${ }^{13} \mathrm{C}$ contribution to $(\mathrm{Hyp}-\mathrm{H})^{-}$at $\mathrm{m} / \mathrm{z}$ 136. The dominant anion observed in this study is the closed-shell dehydrogenated anion, $(\mathrm{Hyp}-\mathrm{H})^{-}$, which exhibits a sharp resonance at $1.1 \mathrm{eV}$. For many nucleobases, including now Hyp, the dehydrogenated anions are the dominant fragments formed upon DEA, which has been suggested to be driven by the high electron affinities of their (Parent $-\mathrm{H})$ radicals $[5,19]$. A relatively high electron affinity for the corresponding (Hyp - H) radicals was also obtained in our computations. Hydrogen loss from either the N1 or the N9 site of the keto-N1H,N9H Hyp tautomer is most probable based on DEA experiments of similarly structured nucleobases and our present calculations. The low dipole moment and lack of a dipole-bound anion for the dominant keto-N1H,N7H tautomer suggests that the keto-N1H,N9H tautomer is primarily responsible for the $(\mathrm{Hyp}-\mathrm{H})$ anion signal observed in our experiments at $453 \mathrm{~K}$. The $1.1 \mathrm{eV}$ resonance for $(\mathrm{Hyp}-\mathrm{H})^{-}$is in a similar position to the (Parent $-\mathrm{H}$ ) anion resonances observed for other nucleobases, including Ade [5] and Thy [3, 17], and may occur via a dipole-bound anion state of the keto-N1H,N9H Hyp that could be coupled to a vibrational Feshbach resonance. The (Parent $-\mathrm{H})^{-}$appears to be a fingerprint characteristic of most nucleobases. Future isotopically-labeled or methylated-Hyp experiments may further clarify the positional origin of the $(\mathrm{Hyp}-\mathrm{H})$ anion. Also, unlike Ade, we do not observe the loss of $\mathrm{NH}_{2}$ or $\mathrm{NH}_{3}$. However, the abstraction of neutral $\mathrm{NH}$ to form $\mathrm{m} / \mathrm{z} 121$ is observed at low-electron energies, although in very small abundance. A variety of anions are observed from Hyp between 5 and $7 \mathrm{eV}$, including $\mathrm{O}^{-}, \mathrm{CN}^{-}, \mathrm{OCN}^{-}, \mathrm{C}_{3} \mathrm{NO}^{-} / \mathrm{HC}(\mathrm{HCN}) \mathrm{CN}^{-}, \mathrm{C}_{4} \mathrm{H}_{2} \mathrm{~N}_{3}^{-}$, and $\mathrm{C}_{4} \mathrm{H}_{3} \mathrm{~N}_{4}^{-}$/ $\mathrm{C}_{4} \mathrm{HN}_{3} \mathrm{O}^{-}$, with $\mathrm{CN}^{-}$and $\mathrm{C}_{4} \mathrm{H}_{2} \mathrm{~N}_{3}^{-}$dominating at these energies. These anions form due to complex 
dissociation reactions or simple bond cleavage from the ring structures of Hyp. Interestingly, the intact imidazole ring can fragment from the parent structure $(\mathrm{m} / \mathrm{z} 66)$. The formation of anions from the DEA to Hyp is relevant to the radiation damage community because of the many possible pathways of decomposition of the Hyp ring structure, which could effectively prevent the participation of Hyp in wobble base pairing in tRNA.

\section{ACKNOWLEDGMENTS}

M.M.D., I.C. and S.P. would like to thank the U.S. Department of Energy Office of Science, Office of Basic Energy Sciences under Award Number DE-FC02-04ER15533 for support and funds for M.M.D.'s travel to the Innsbruck lab to perform the experiments. This is Radiation Laboratory document number NDRL-5059. This work was also supported by the Fonds zur Förderung der wissenschaftlichen Forschung (Austrian Science Fund (FWF) P22665). 


\section{FIGURES}
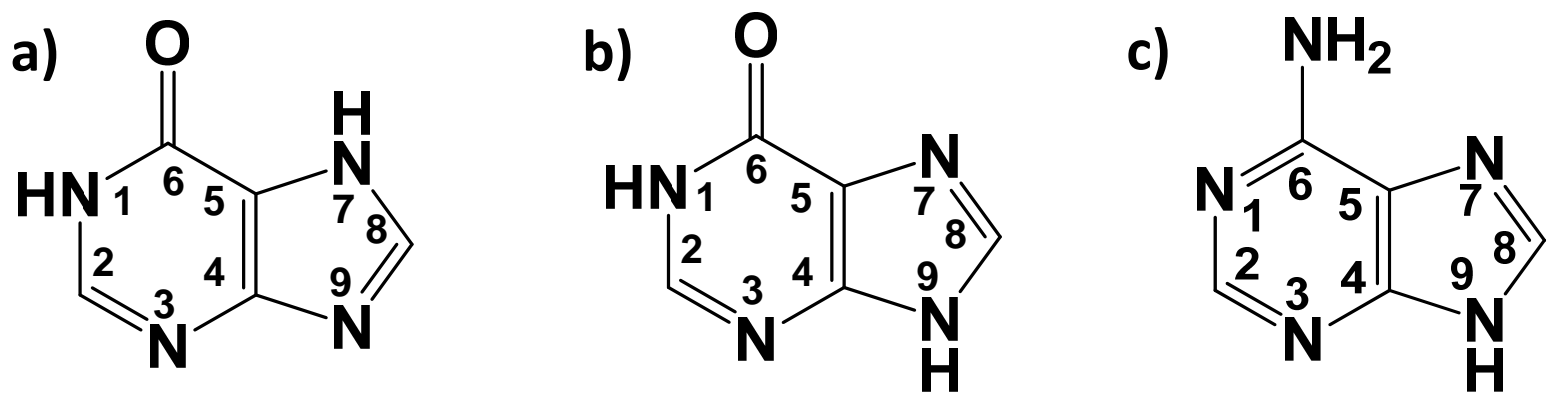

Fig. 1. Chemical structures of the two most stable tautomers of hypoxanthine in the gas phase:

(a) keto-N1H,N7H hypoxanthine and (b) keto-N1H,N9H hypoxanthine. For comparison, the most stable tautomer of adenine in the gas phase is also provided: (c) N9H adenine. 


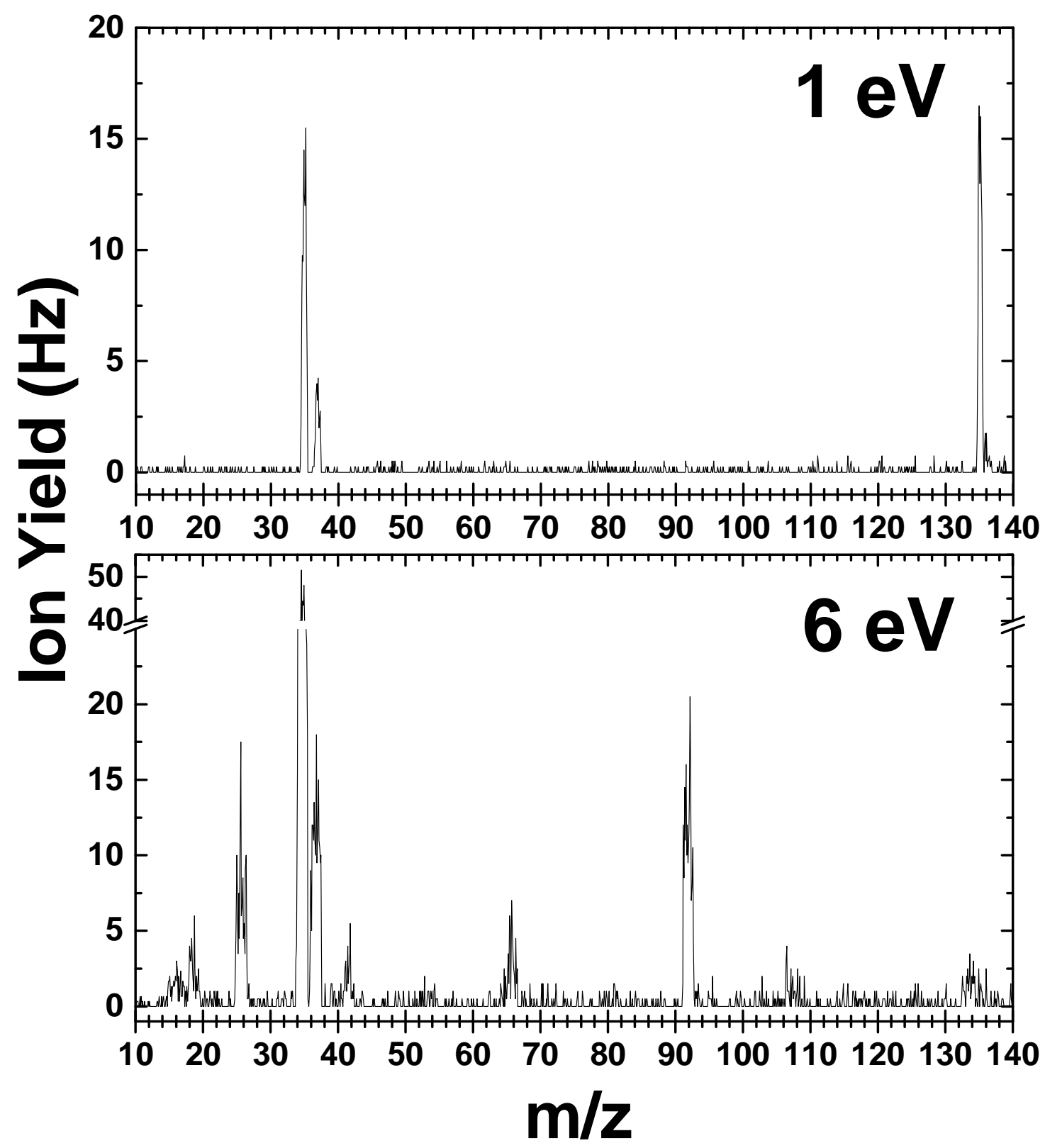

Fig. 2. Anion mass spectra of hypoxanthine measured at incident electron energies of 1 and $6 \mathrm{eV}$ taken at an oven temperature of $453 \pm 3 \mathrm{~K}$. The peaks at $\mathrm{m} / \mathrm{z} 35$ and $\mathrm{m} / \mathrm{z} 37$ are due to the calibration gas, $\mathrm{CCl}_{4}$. The pressure, ion yields, and mass resolution slightly varied depending upon the experiment $\left(2 \times 10^{-6}\right.$ to $\left.2 \times 10^{-7} \mathrm{mbar}\right)$, and the mass scales were calibrated after each experiment. 


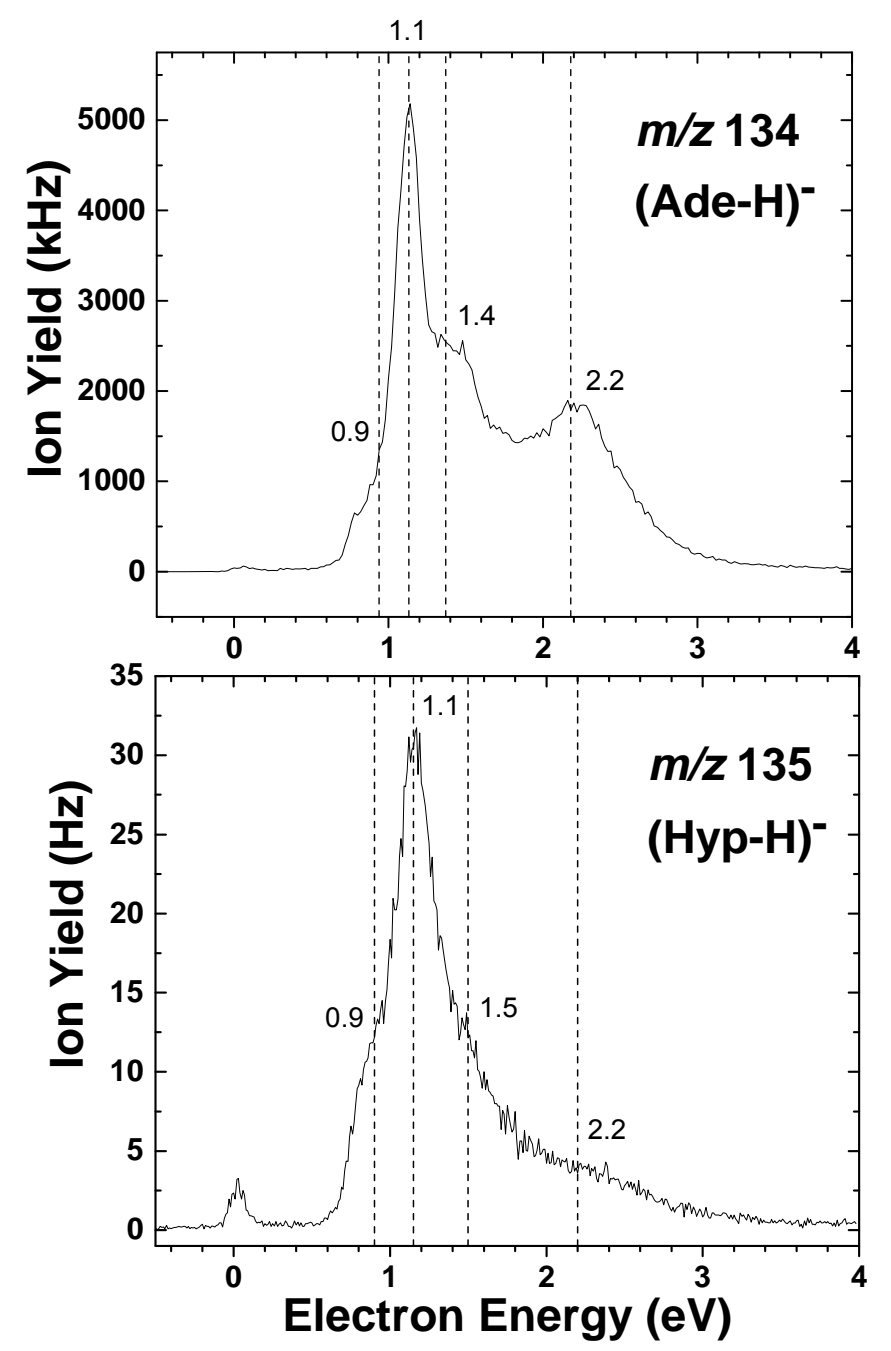

Fig. 3. Ion efficiency curve of $m / z 135$ for $(\mathrm{Hyp}-\mathrm{H})^{-}$induced by electron attachment to hypoxanthine (bottom) taken at an oven temperature of $453 \pm 3 \mathrm{~K}$ compared with $\mathrm{m} / \mathrm{z} 134$ for (Ade $-\mathrm{H}$ ) ${ }^{-}$induced by electron attachment to adenine (top) both as a function of electron energy below $4 \mathrm{eV}$ and at a resolution of $\sim 110 \mathrm{meV}$. 


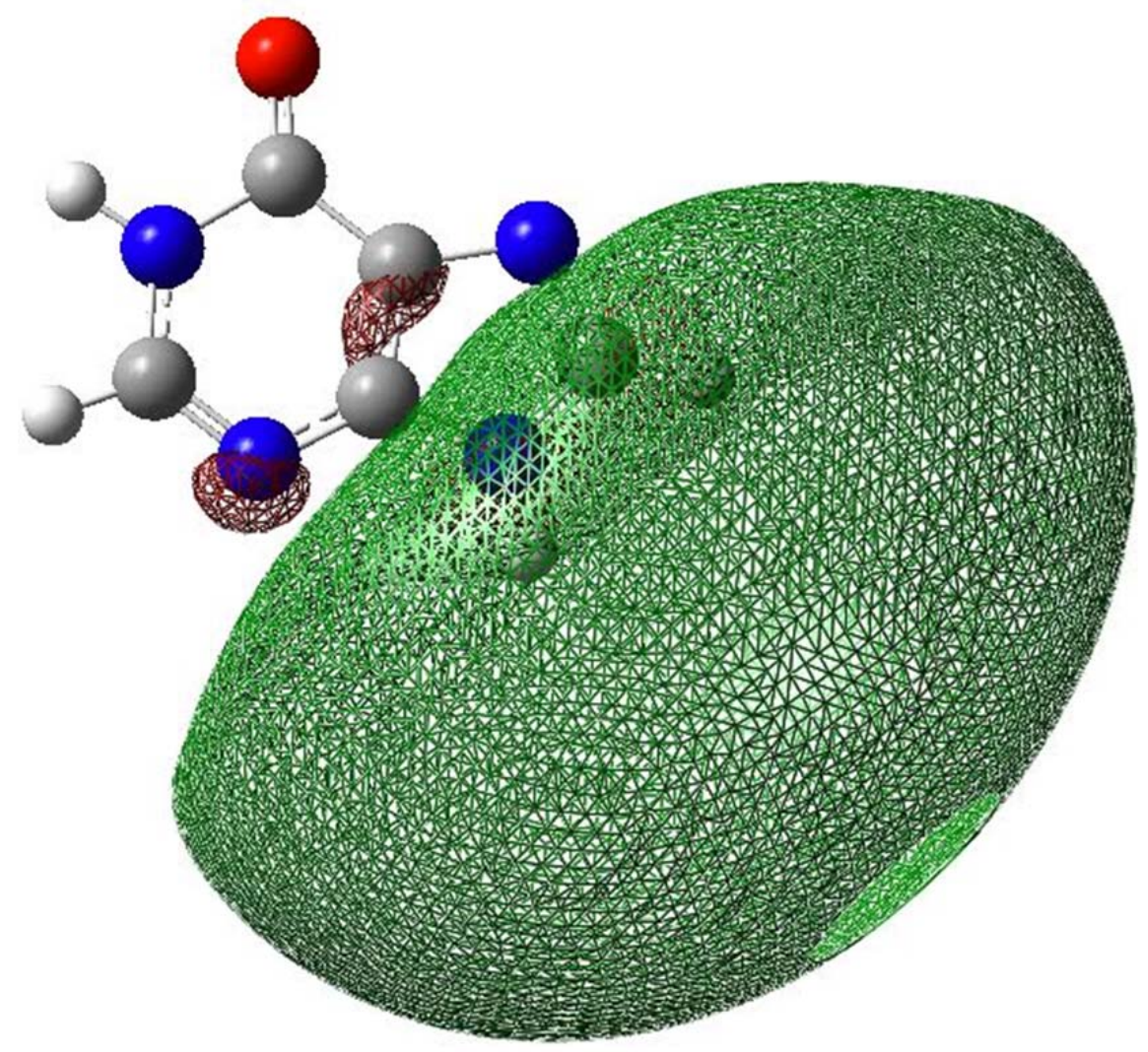

Fig. 4. Molecular orbital spin density plot of the keto-N1H,N9H highest occupied orbital in the dipole-bound anion (somo) of hypoxanthine, calculated using the U(MP2-aug-cc-pVDZ+) method. 


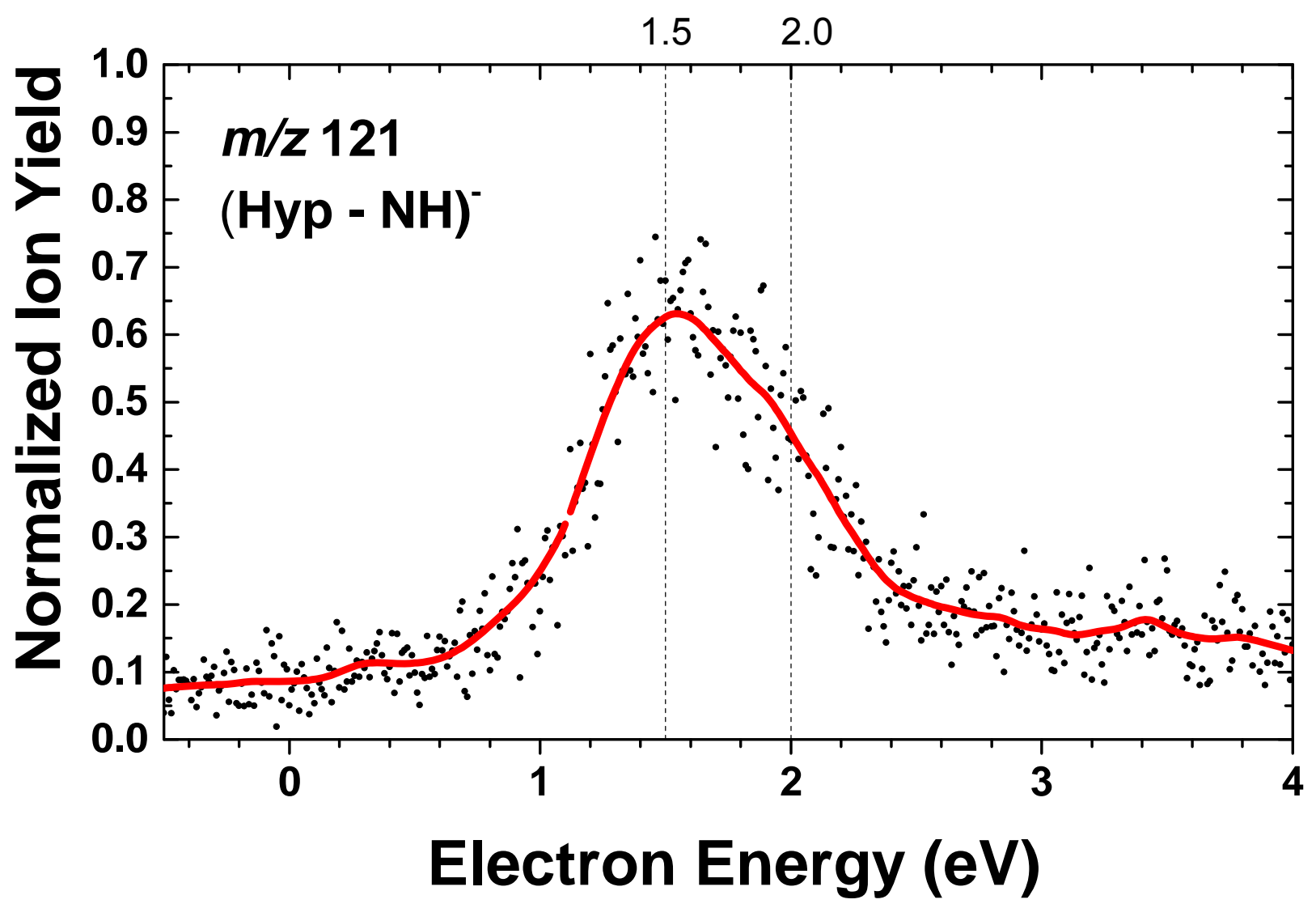

Fig. 5. Ion efficiency curve of $m / z 121$ for $(\mathrm{Hyp}-\mathrm{NH})^{-}$induced by electron attachment to hypoxanthine as a function of electron energy, taken at an oven temperature of $453 \pm 3 \mathrm{~K}$. Red line is provided only to guide the eye. 

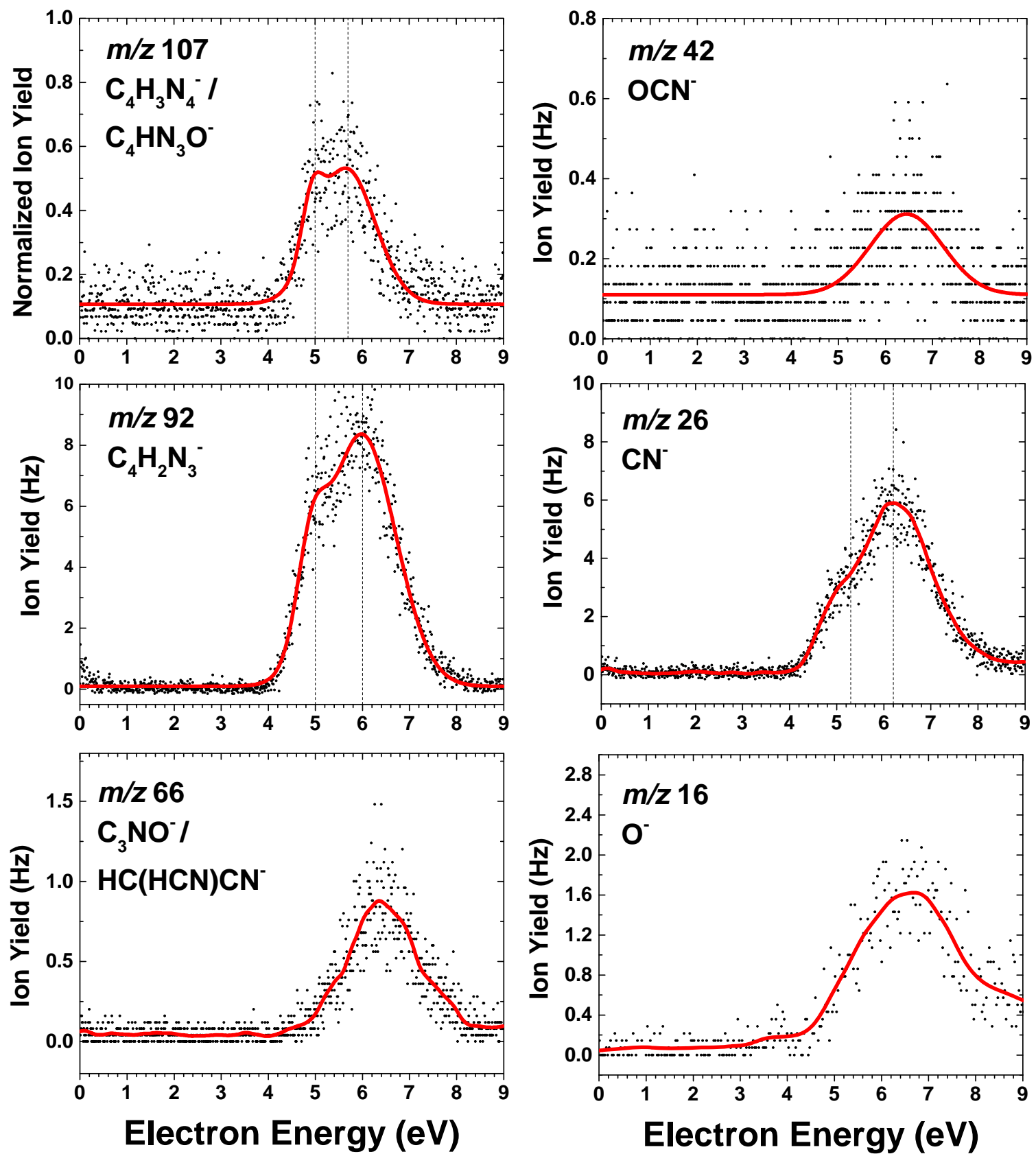

Fig. 6. Ion efficiency curves of $m / z 107, m / z ~ 92, m / z ~ 66, m / z ~ 42, m / z ~ 26$, and $m / z 16$ induced by electron attachment to hypoxanthine as a function of electron energy below $9 \mathrm{eV}$ taken at an oven temperature of $453 \pm 3 \mathrm{~K}$. Red lines are provided only to guide the eye. 


\section{TABLES}

Table 1. Anionic species, relative abundances to $(\mathrm{Hyp}-\mathrm{H})^{-}$, masses, and the resonant peak positions for fragments formed upon DEA to hypoxanthine listed from the largest to smallest mass. Comparable fragments from the DEA to adenine from ref. [5] are also provided.

\begin{tabular}{|c|c|c|c|c|c|c|}
\hline \multicolumn{4}{|c|}{ Hypoxanthine $\left(\mathrm{C}_{5} \mathrm{H}_{4} \mathrm{~N}_{4} \mathrm{O}-\mathrm{m} / \mathrm{z} 136\right)$} & \multicolumn{3}{|c|}{ Adenine $\left(\mathrm{C}_{5} \mathrm{H}_{5} \mathrm{~N}_{5}-\mathrm{m} / \mathrm{z} 135\right)[5]$} \\
\hline Anion & $\begin{array}{l}\text { Relative } \\
\text { Abundance }\end{array}$ & $\begin{array}{l}\text { Mass } \\
(\mathrm{m} / \mathrm{z})\end{array}$ & $\begin{array}{c}\text { Peak } \\
\text { position } \\
(\mathrm{eV})\end{array}$ & Anion & $\begin{array}{l}\text { Mass } \\
(\mathrm{m} / \mathrm{z})\end{array}$ & $\begin{array}{c}\text { Peak } \\
\text { position } \\
(\mathrm{eV})\end{array}$ \\
\hline $\begin{array}{c}(\mathrm{Hyp}- \\
\mathrm{H})^{-}\end{array}$ & 100 & 135 & $\begin{array}{c}0.03, \\
0.9,1.1, \\
1.5,2.2 \\
\end{array}$ & $\left(\right.$ Ade $-\mathrm{H}^{-}$ & 134 & $\begin{array}{c}* 0.08 \\
0.9,1.1 \\
1.4,2.2\end{array}$ \\
\hline $\begin{array}{l}\text { (Hyp - } \\
\text { NH) }\end{array}$ & 0.9 & 121 & $1.5,2.0$ & $\left(\text { Ade }-\mathrm{NH}_{2}\right)^{-}$ & 119 & $0,1.1,5.7$ \\
\hline $\begin{array}{l}\mathrm{C}_{4} \mathrm{H}_{3} \mathrm{~N}_{4}{ }^{-} / \\
\mathrm{C}_{4} \mathrm{HN}_{3} \mathrm{O}^{-}\end{array}$ & 1.9 & 107 & $5.0,5.7$ & $\mathrm{C}_{4} \mathrm{H}_{3} \mathrm{~N}_{4}^{-}$ & 107 & $5.7,10$ \\
\hline $\mathrm{C}_{4} \mathrm{H}_{2} \mathrm{~N}_{3}{ }^{-}$ & 24 & 92 & $5.0,6.0$ & $\mathrm{C}_{4} \mathrm{H}_{2} \mathrm{~N}_{3}{ }^{-}$ & 92 & $5.6,6.7$ \\
\hline $\begin{array}{c}\mathrm{C}_{3} \mathrm{NO}^{-} / \\
\mathrm{HC}(\mathrm{HCN}) \\
\mathrm{CN}^{-}\end{array}$ & 20 & 66 & 6.3 & $\mathrm{HC}(\mathrm{CN})_{2}^{-}$ & 65 & $\begin{array}{c}5.8,6.6 \\
10.6\end{array}$ \\
\hline $\mathrm{OCN}^{-}$ & 0.9 & 42 & 6.4 & $\begin{array}{l}\mathrm{CHN}_{2}^{-}{ }^{-} \\
\mathrm{C}_{2} \mathrm{H}_{3} \mathrm{~N}^{-}\end{array}$ & 41 & $\begin{array}{c}5.7,6.7 \\
11.4\end{array}$ \\
\hline $\mathrm{CN}^{-}$ & 17 & 26 & $5.3,6.2$ & $\mathrm{CN}^{-}$ & 26 & $\begin{array}{c}5.8,6.7 \\
11.5\end{array}$ \\
\hline $\mathrm{O}^{-}$ & 5 & 16 & 6.6 & -- & -- & -- \\
\hline
\end{tabular}

* Positions given are for the $110 \mathrm{meV}$ resolution data shown in Fig. 3. 


\section{REFERENCES}

${ }^{1}$ L. Sanche, Mass Spectrom. Rev. 21, 349 (2002).

${ }^{2}$ H. Abdoul-Carime, J. Langer, M. A. Huels, and E. Illenberger, Eur. Phys. J. D 35, 399 (2005).

${ }^{3}$ S. Ptasińska, S. Denifl, B. Mroz, M. Probst, V. Grill, E. Illenberger, P. Scheier, and T. D. Märk, J. Chem. Phys. 123, 124302 (2005).

${ }^{4}$ S. Ptasińska, S. Denifl, V. Grill, T. D. Märk, E. Illenberger, and P. Scheier, Phys. Rev. Lett. 95, 093201 (2005).

${ }^{5}$ D. Huber, M. Beikircher, S. Denifl, F. Zappa, S. Matejcik, A. Bacher, V. Grill, T. D. Märk, and P. Scheier, J. Chem. Phys. 125, 084304 (2006).

${ }^{6}$ L. Sanche, Eur. Phys. J. D 35, 367 (2005).

${ }^{7}$ E. Illenberger, and J. Momigny, Gaseous Molecular Ions: An Introduction to Elementary Processes Induced by Ionization (Topics in Physical Chemistry) (Springer, New York, 1992), Part III : Electron Attachment Processes in Molecules and Molecular Aggregates.

${ }^{8}$ I. Bald, J. Langer, P. Tegeder, and O. Ingolfsson, Int. J. Mass Spectrom. 277, 4 (2008).

${ }^{9}$ M. M. Dawley, and S. Ptasińska, Int. J. Mass Spectrom. 365-366, 143 (2014).

${ }^{10}$ B. Boudaiffa, P. Cloutier, D. Hunting, M. A. Huels, and L. Sanche, Sci 287, 1658 (2000).

${ }^{11} \mathrm{P}$. Swiderek, Angew. Chem. 45, 4056 (2006).

${ }^{12}$ S. Gohlke, H. Abdoul-Carime, and E. Illenberger, Chem. Phys. Lett. 380, 595 (2003).

${ }^{13}$ S. Denifl, F. Zappa, I. Mahr, J. Lecointre, M. Probst, T. D. Märk, and P. Scheier, Phys. Rev. Lett. 97, 043201 (2006).

${ }^{14}$ S. Denifl, P. Sulzer, D. Huber, F. Zappa, M. Probst, T. D. Märk, P. Scheier, N. Injan, J. Limtrakul, R. Abouaf, and H. Dunet, Angew. Chem. 46, 5238 (2007).

${ }^{15}$ H. Abdoul-Carime, S. Gohlke, and E. Illenberger, Phys. Rev. Lett. 92, 168103 (2004).

${ }^{16}$ B. F. Minaev, M. I. Shafranyosh, Y. Y. Svida, M. I. Sukhoviya, I. I. Shafranyosh, G. V. Baryshnikov, and V. A. Minaeva, J. Chem. Phys. 140, 175101 (2014).

${ }^{17}$ S. Denifl, S. Ptasińska, M. Probst, J. Hrusak, P. Scheier, and T. D. Märk, J. Phys. Chem. A 108, 6562 (2004). 
${ }^{18}$ F. F. da Silva, C. Matias, D. Almeida, G. Garcia, O. Ingolfsson, H. D. Flosadottir, B. Omarsson, S. Ptasińska, B. Puschnigg, P. Scheier, P. Limao-Vieira, and S. Denifl, J. Am. Soc. Mass Spectrom. 24, 1787 (2013).

${ }^{19}$ G. Hanel, B. Gstir, S. Denifl, P. Scheier, M. Probst, B. Farizon, M. Farizon, E. Illenberger, and T. D. Märk, Phys. Rev. Lett. 90, 188104 (2003).

${ }^{20}$ F. H. C. Crick, J. Mol. Biol. 19, 548 (1966).

${ }^{21}$ O. O. Brovarets, and D. M. Hovorun, J. Biomol. Struct. Dyn. 31, 913 (2013).

${ }^{22}$ S. Ptasińska, S. Denifl, S. Gohlke, P. Scheier, E. Illenberger, and T. D. Märk, Angew. Chem. 45, 1893 (2006).

${ }^{23}$ S. Ptasińska, S. Denifl, P. Scheier, E. Illenberger, and T. D. Märk, Angew. Chem. 44, 6941 (2005).

${ }^{24}$ S. Ptasińska, S. Denifl, P. Scheier, and T. D. Märk, Int. J. Mass Spectrom. 243, 171 (2005).

${ }^{25}$ S. Ptasińska, P. Candori, S. Denifl, S. Yoon, V. Grill, P. Scheier, and T. D. Märk, Chem. Phys. Lett. 409, 270 (2005).

${ }^{26}$ M. M. Dawley, K. Tanzer, W. A. Cantrell, P. Plattner, N. R. Brinkmann, P. Scheier, S. Denifl, and S. Ptasińska, Phys. Chem. Chem. Phys. 16, 25039 (2014).

${ }^{27}$ K. Tanzer, A. Pelc, S. E. Huber, Z. Czupyt, and S. Denifl, J. Chem. Phys. 142, 034301 (2015).

${ }^{28}$ S. Matejcik, A. Kiendler, A. Stamatovic, and T. D. Märk, Int. J. Mass Spectrom. Ion Processes 149150, 311 (1995).

${ }^{29}$ M. E. Costas, and R. Acevedo-Chavez, J. Solution Chem. 41, 864 (2012).

${ }^{30}$ B. Hernandez, F. J. Luque, and M. Orozco, J. Org. Chem. 61, 5964 (1996).

${ }^{31}$ A. Alparone, Chem. Phys. 410, 90 (2013).

${ }^{32}$ J. Lin, C. Yu, S. Peng, I. Akiyama, K. Li, L. K. Lee, and P. R. Lebreton, J. Phys. Chem. 84, 1006 (1980).

${ }^{33}$ M. E. Costas, and R. AcevedoChavez, J. Phys. Chem. A 101, 8309 (1997).

${ }^{34}$ M. J. Frisch, G. W. Trucks, H. B. Schlegel, G. E. Scuseria, M. A. Robb, J. R. Cheeseman, G. Scalmani, V. Barone, B. Mennucci, G. A. Petersson, H. Nakatsuji, M. Caricato, X. Li, H. P. Hratchian, A. F. Izmaylov, J. Bloino, G. Zheng, J. L. Sonnenberg, M. Hada, M. Ehara, K. Toyota, R. Fukuda, J. Hasegawa, M. Ishida, T. Nakajima, Y. Honda, O. Kitao, H. Nakai, T. Vreven, J. Montgomery, J. E. Peralta, F. Ogliaro, M. Bearpark, J. J. Heyd, E. Brothers, K. N. Kudin, V. N. Staroverov, R. Kobayashi, J. Normand, K. Raghavachari, A. Rendell, J. C. Burant, J. M. Millam, S. S. Iyengar, J. Tomasi, M. Cossi, N. Rega, J. M. Millam, M. Klene, J. E. Knox, J. B. Cross, V. Bakken, C. Adamo, J. Jaramillo, R. Gomperts, R. E. Stratmann, O. Yazyev, A. J. 
Austin, R. Cammi, C. Pomelli, J. W. Ochterski, R. L. Martin, K. Morokuma, V. G. Zakrzewski, G. A. Voth, P. Salvador, J. J. Dannenberg, S. Dapprich, A. D. Daniels, O. Farkas, J. B. Foresman, J. V. Ortiz, J. Cioslowski, and D. J. Fox, (Gaussian, Inc., Wallingford, CT, 2009).

${ }^{35}$ A. D. Becke, J. Chem. Phys. 98, 5648 (1993).

${ }^{36}$ R. Krishnan, J. S. Binkley, R. Seeger, and J. A. Pople, J. Chem. Phys. 72, 650 (1980).

${ }^{37}$ C. Desfrancois, V. Periquet, S. Carles, J. P. Schermann, D. M. A. Smith, and L. Adamowicz, J. Chem. Phys. 110, 4309 (1999).

${ }^{38}$ R. A. Kendall, T. H. Dunning, and R. J. Harrison, J. Chem. Phys. 96, 6796 (1992).

${ }^{39}$ M. K. Shukla, and J. Leszczynski, Wiley Interdisciplinary Reviews-Computational Molecular Science 3, 637 (2013).

${ }^{40}$ P. D. Burrow, G. A. Gallup, A. M. Scheer, S. Denifl, S. Ptasińska, T. Märk, and P. Scheier, J. Chem. Phys. 124, 124310 (2006).

${ }^{41}$ A. M. Scheer, K. Aflatooni, G. A. Gallup, and P. D. Burrow, Phys. Rev. Lett. 92, 068102 (2004).

${ }^{42}$ S. B. King, M. A. Yandell, A. B. Stephansen, and D. M. Neumark, J. Chem. Phys. 141 (2014).

${ }^{43}$ E. D. Raczynska, M. Makowski, K. Zientara-Rytter, K. Kolczynska, T. M. Stepniewski, and M. Hallmann, J. Phys. Chem. A 117, 1548 (2013).

${ }^{44}$ C. Koenig-Lehmann, J. Kopyra, I. Dabkowska, J. Kocisek, and E. Illenberger, Phys. Chem. Chem. Phys. 10, 6954 (2008).

${ }^{45}$ NIST Chemistry WebBook, NIST Standard Reference Database Number 69, edited by P. J. Linstrom, and W. G. Mallard, National Institute of Standards and Technology, Gaithersburg, MD 20899.

${ }^{46}$ CRC Handbook of Chemistry and Physics, Internet Version 2013, edited by D. R. Lide, Boca Raton, FL. 